This item was submitted to Loughborough's Research Repository by the author.

Items in Figshare are protected by copyright, with all rights reserved, unless otherwise indicated.

\title{
How does sediment supply influence refugia availability in river widenings?
}

PLEASE CITE THE PUBLISHED VERSION

https://doi.org/10.1080/24705357.2020.1831415

PUBLISHER

Informa UK Limited

VERSION

AM (Accepted Manuscript)

PUBLISHER STATEMENT

This is the Author's Original Manuscript of an article published by Taylor \& Francis in Journal of Ecohydraulics on 01 Feb 2021, available online: https://doi.org/10.1080/24705357.2020.1831415

\section{LICENCE}

CC BY-NC-ND 4.0

\section{REPOSITORY RECORD}

Rachelly, Cristina, Kate Mathers, Christine Weber, Volker Weitbrecht, Robert M Boes, and David F Vetsch. 2021. "How Does Sediment Supply Influence Refugia Availability in River Widenings?". Loughborough University. https://hdl.handle.net/2134/13696252.v1. 


\title{
How does sediment supply influence refugia availability in river widenings?
}

\author{
Cristina Rachelly ${ }^{\mathrm{a}}$, Kate L. Mathers ${ }^{\mathrm{b}}$, Christine Weber ${ }^{\mathrm{b}}$, Volker Weitbrecht ${ }^{\mathrm{a}}$, Robert \\ M. Boes ${ }^{\mathrm{a}}$, and David F. Vetsch ${ }^{\mathrm{a}}$ \\ ${ }^{a}$ Laboratory of Hydraulics, Hydrology and Glaciology (VAW), ETH Zurich, Switzerland \\ ${ }^{b}$ Eawag, Swiss Federal Institute of Aquatic Science and Technology, Department of Surface \\ Waters Research and Management, Kastanienbaum, Switzerland
}

\section{ARTICLE HISTORY}

Compiled September 17, 2020

\begin{abstract}
Habitats that mitigate the effects of a disturbance event (e.g. flood) are referred to as refugia. Their occurrence in heavily impacted river systems is often limited, and their restoration rarely pursued. This paper presents the results of a combined laboratory and numerical modeling study to assess flood refugia availability to mobile aquatic organisms in the context of river restoration and dynamic river widening. We used a calibrated 2D hydrodynamic model based on eight topographies obtained in laboratory experiments to assess refugia availability by analyzing the hydro-morphological conditions under varying sediment supply. Overall, sediment equilibrium sustains more complex hydro-morphological conditions with low bed shear stress zones being maintained during elevated discharges. Furthermore, our results suggest that the floodplain is an important potential refuge that becomes accessible for discharges with a return period of approximately one year. Conversely, sediment deficit results in a homogeneous flow field with steadily increasing hydraulic forces for high flows and impaired lateral connectivity except for very large flood events of a 30- to 100-year return period. Dynamic river widening implemented in a channel with sediment equilibrium conditions as opposed to a sediment deficit is thus more likely to provide flood refugia.
\end{abstract}

CONTACT Cristina Rachelly Email: rachelly@vaw.baug.ethz.ch 


\section{KEYWORDS}

river restoration, dynamic river widening, hydrodynamic modeling, habitat

availability, flood refugia 


\section{Introduction}

An intricate and episodically changing habitat mosaic is a vital part of a natural river system (Stanford et al. 2005). The habitat mosaic is strongly influenced by the diverse morphologies a river can assume and these are in turn the result of interacting geomorphological, hydrological, and biological processes (Castro and Thorne 2019). These driving processes can be highly dynamic and act on various spatial and temporal scales (Poff et al. 1997; Gurnell et al. 2002; Wohl et al. 2015a). When the characteristics of a biotic or abiotic process, i.e. its intensity or duration, assume exceptional values, the process is referred to as a disturbance (Resh et al. 1988; Lake 2000). Examples of abiotic disturbances include floods (e.g. Lepori and Hjerdt 2006), droughts (e.g. Wood et al. 2010), or ice formation (e.g. Weber et al. 2013). The temporal variation of the disturbing force can be used to classify disturbance events into pulse, press, or ramp events (Lake 2000). Pulses are short, sharply delineated events, press events have an instantaneous start with the pressure subsequently maintained, and a ramp is a steadily increasing disturbing force.

A flood event is a major form of pulse disturbance and induces hydraulic stress as well as sediment and large wood transport in the affected river (e.g. Sedell et al. 1990; Lake 2000; Lepori and Hjerdt 2006; Czuba et al. 2018). Aquatic organisms may be displaced, injured, or killed (Lake 2000). However, the stream communities usually recover fairly rapidly (e.g. Lake 2000; Gjerløv et al. 2003; Lepori and Hjerdt 2006), indicating that a certain number of organisms can resist the disturbing force. Despite the apparent adverse effects of hydrological disturbance events for stream organisms, high magnitude flood events are a critical component of the natural flow regime and are vital for maintaining healthy ecosystem functioning (Poff et al. 1997; Richter et al. 1997).

Disturbance intensity may vary widely between habitats due to their spatial arrangement, substrate characteristics, or the acting hydraulic forces (Weber et al. 2013). Habitats that mitigate the effects of a disturbance on the biota and enable organisms to resist the disturbance are typically referred to as refugia (Lake 2000). They exist at various spatial and temporal scales (e.g. Sedell et al. 1990; Lancaster and Belyea 
1997; Lancaster 2000) and their refugia function depends on various factors such as the disturbance type (e.g. Lake 2000), organism characteristics (e.g. Pearsons et al. 1992; Weber et al. 2013; Sueyoshi et al. 2014), substrate composition (e.g. Mathers et al. 2019), and hydro-morphological conditions (e.g. Lancaster and Hildrew 1993; Rice et al. 2007). Examples of local flood refugia are low bed shear stress zones (e.g. Lancaster and Hildrew 1993; Winterbottom et al. 1997; Lancaster 2000), specific turbulent eddies (e.g. Schwartz and Herricks 2005), marginal zones (e.g. Rempel et al. 1999), individual stones (e.g. Townsend et al. 1997; Matthaei et al. 2000), or woody debris (e.g. Palmer et al. 1996). On a larger scale, the floodplain (e.g. Matthaei and Townsend 2000; Schwartz and Herricks 2005), the hyporheic zone (e.g. Dole-Olivier et al. 1997; Stubbington 2012), or tributaries (e.g. Sueyoshi et al. 2014) may serve as refugia. It is commonly assumed that the closer a reach is to its natural state the more heterogeneous its habitats will be, thereby providing ample refugia opportunities under a range of hydrological conditions (Sedell et al. 1990; Pearsons et al. 1992; Gjerløv et al. 2003). In particular, a more morphologically and hydraulically complex reach will likely preserve low bed shear stress zones during periods of elevated discharge (e.g. Pearsons et al. 1992; Lancaster and Hildrew 1993).

However, extensive anthropogenic impact on fluvial environments has destructed or degraded habitats and disrupted ecosystem processes (Dudgeon et al. 2006). Rivers across the globe have become channelized, reducing the available habitat area and homogenizing the remaining habitats (e.g. Hohensinner et al. 2001). Damming, gravel extraction, and protective structures have further disrupted ecosystem processes associated with the flow and sediment regime (Kondolf 1997). At first, the flow regime received most attention (Poff et al. 1997) before it was recognized that other processes, such as sediment and large wood transport, play an equally important role in shaping fluvial ecosystems (Gurnell et al. 2002; Wohl et al. 2015a).

Sediment transport is a highly episodic and heterogeneous process because it depends on the interaction of bed shear stresses inflicted by near-bed hydraulic forces and the mobility of the sediment (Wohl et al. 2015a). In general, the larger the grain the higher the bed shear stress necessary to mobilize it. However, the entrainment process is further complicated by hiding and exposure effects (larger grains are more 
exposed to the flow while hiding the smaller grains) that are especially relevant for the poorly sorted sediment of gravel-bed rivers (e.g. Wilcock and Crowe 2003). This leads to a diverse and dynamic mosaic of riverbed patches with active and inactive bed-load transport and different grain sizes (Nelson et al. 2009).

A river's transport capacity is controlled by channel geometry, discharge, sediment characteristics and supply (Kondolf 1997). Sediment supply that matches the longterm (years to decades) average transport capacity of a river reach is defined as sediment equilibrium. Conversely, the long-term shortage of sediment supply compared to the river's transport capacity is referred to as sediment deficit (Kondolf 1997). The geomorphic implications of sediment deficit on fluvial systems include channel narrowing and incision into the surrounding floodplain (e.g. Surian and Rinaldi 2003), surface coarsening (e.g. Dietrich et al. 1989), and the expansion of inactive patches, i.e. without frequent changes in river bed elevation and grain size composition (e.g. Nelson et al. 2009). Assuming that habitat units of higher complexity and dynamics are more likely to provide refugia (e.g. Sedell et al. 1990; Gjerløv et al. 2003), sediment deficit may, therefore, impair refugia availability and result in less resistant and resilient stream communities.

In recent decades, great efforts have been made to restore fluvial ecosystems (e.g. Bernhardt et al. 2005). However, lack of awareness for the complex biotic and abiotic interactions often lead to restoration projects that are overly focused on constructing specific structures and may fail to deliver long-term benefits (Beechie et al. 2010; Wohl et al. 2015b). Among others, Beechie et al. (2010) and Wohl et al. (2015b) argue for a restoration practice that emphasizes intact ecosystem processes and functions, such as focusing on the refuge function of certain habitats during disturbance events, as opposed to only residential habitats during mean flow conditions.

An example of process-focused restoration is dynamic river widening, a reach-scale measure to mitigate the effects of channelization (e.g. Rohde et al. 2005; Habersack and Piégay 2007; Williams et al. 2020). On one or both sides of the river channel, bank protection is removed within a limited reach to enable lateral erosion of the adjacent floodplain. During subsequent flood events, the channel is widened by hydrodynamic forces and thus the morphology tends to become more complex (e.g. Garcia Lugo et al. 
2015; Williams et al. 2020). The erodible area is usually constricted due to nearby infrastructure. Hidden bank protection measures along the outermost boundary of the widening can limit lateral erosion. 'Dynamic' emphasizes the focus on the reactivation of morphodynamic processes in contrast to widenings that are constructed with a predefined width. Given that dynamic river widening is a reach-scale measure, the restoration effect may be linked to processes acting on a larger scale, for example the sediment supply (Wohl et al. 2015b; Rachelly et al. 2018).

As field observations during flood events are very challenging, refugia availability during floods is less well understood than during drought. We therefore used a combined approach of laboratory and numerical modeling (cf. Vanzo et al. 2016) to study flood refugia availability in dynamic river widenings. We were specifically interested in the impact of the sediment supply level, in particular the effects of a sediment deficit versus sediment equilibrium on refugia availability for mobile aquatic organisms such as fish or invertebrates. From the laboratory experiments, we obtained high-resolution topographical data and information on bed-load transport processes. Using numerical simulations, we were able to determine the hydraulic conditions in great detail and extend the study to a wide range of discharges.

We addressed the following research questions:

(1) Does the sediment supply level influence the inundation of the floodplain and therefore its availability as a potential flood refuge? We hypothesize that the morphological and topographical conditions developed under equilibrium sediment supply enhance the channel-floodplain connectivity (e.g. Hohensinner et al. 2003). In contrast, sediment deficit may lead to incision and the decoupling between main channel and floodplain (e.g. Surian and Rinaldi 2003).

(2) Does the sediment supply level significantly affect the hydro-morphological conditions across a range of discharges? We hypothesize that a widening subjected to equilibrium sediment supply develops a more diverse morphology in contrast to a reach with a sediment deficit (Rachelly et al. 2018). In consequence, the hydraulic variability may be higher and zones of low bed shear stress acting as refugia may persist during high flows (e.g. Lancaster and Hildrew 1993).

(3) Does the sediment supply level modify the spatial extent of riverbed elevation 
change and how does this affect refugia availability? We hypothesize that while equilibrium sediment supply invokes more extensive sediment relocation (Dietrich et al. 1989; Nelson et al. 2009) and thus aggravates the disturbance (e.g. Matthaei and Townsend 2000), the overall impact of equilibrium sediment supply on refugia availability is beneficial. 


\section{Methods}

\subsection{Case study Kander River}

This study reproduces the general conditions in the Kander River, a subalpine gravelbed river in Switzerland, as the case study example (Figure 1a). Prior to the channelization of the Kander River in the 20th century, its morphology was wandering to braiding, whereas it is now a single channel with a mostly flat bed. Within the scope of a long-term restoration program, several dynamic river widenings are planned to be implemented, and this study system therefore provides an opportunity to assess the restoration effect of such widenings.
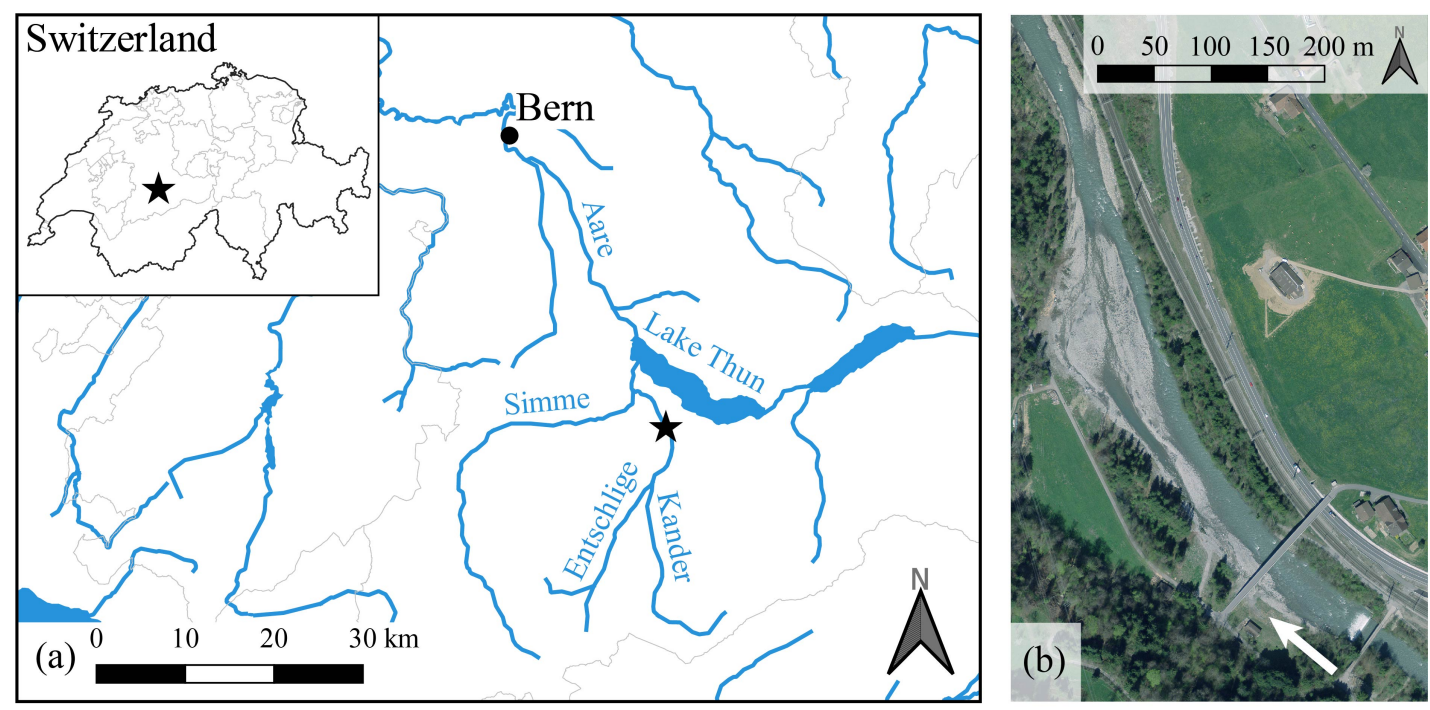

Figure 1. (a) Location of the Kander River in the Canton of Bern, Switzerland, and (b) an example of a dynamic river widening at $\mathrm{N} 46^{\circ} 39^{\prime} 14.755^{\prime \prime} \mathrm{E} 7^{\circ} 40^{\prime} 48.398^{\prime \prime}(\star)$ in the year 2010. This widening developed in the year 2005 during a flood event with a return period of approximately 50 years (Sources: (a) FOEN (2014); swisstopo (2018), (b) (C) swisstopo).

An example of an already existing dynamic river widening can be found at $\mathrm{N} 46^{\circ} 39^{\prime} 14.755^{\prime \prime} \mathrm{E} 7^{\circ} 40^{\prime} 48.398^{\prime \prime}$, where a flood with a return period of approximately 50 years in 2005 caused lateral erosion over a length of approximately $600 \mathrm{~m}$ (Figure $1 \mathrm{~b})$. In this river section, the still channelized river has a slope of roughly 0.01 , a bed width of 20-25 m, and banks protected by riprap or groins (FOEN 2015). The grain size distribution is that of a poorly sorted gravel-bed river, with a geometric 
standard deviation $\sigma_{g}=\left(D_{84} / D_{16}\right)^{0.5}=3.4$, and the characteristic grain diameters $D_{50}=0.058 \mathrm{~m}$ and $D_{90}=0.188 \mathrm{~m}$ (Huwiler and Stocker 2019). The flow regime of the Kander River is nivo-glacial (Weingartner and Aschwanden 1992) and the flood season lasts from May to August (FOEN 2017, see Table 1 for characteristic discharges).

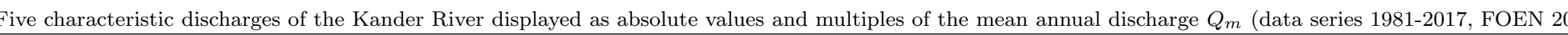

\begin{tabular}{|c|c|c|c|c|}
\hline & & $\begin{array}{c}Q \\
\left(\mathrm{~m}^{3} / \mathrm{s}\right)\end{array}$ & $\begin{array}{c}Q / Q_{m} \\
(-)\end{array}$ & Relevance \\
\hline al discharge & $Q_{m}$ & 20.4 & 1 & Baseflow conditions \\
\hline thly discharge in June & $Q_{m, \text { June }}$ & 41.3 & 2 & Baseflow conditions during the flood season \\
\hline h return period of 1.5 years & $\mathrm{H} Q_{1.5}$ & 118.3 & 5.8 & Bedforming discharge; corresponds to steady bedforming discharge (BQ) in the laboratory expe \\
\hline h return period of 30 years & $\mathrm{H} Q_{30}$ & 244 & 12 & Large flood event; corresponds to the peak flow of the flood hydrograph (FQ) in the laboratory ex \\
\hline h return period of 100 years & $\mathrm{H} Q_{100}$ & 313 & 15.3 & Large flood event \\
\hline
\end{tabular}

\subsection{Laboratory experiments}

Laboratory experiments investigating the dynamic river widening process were performed at the Laboratory of Hydraulics, Hydrology and Glaciology (VAW) at ETH Zurich. All hydraulic (FOEN 2017), sedimentological (Huwiler and Stocker 2019), and geometric (FOEN 2015) parameters were chosen to correspond to the Kander River. The laboratory setup consisted of a straight, trapezoidal channel with fixed banks and a mobile bed. The channel with a slope of 0.01 is $0.89 \mathrm{~m}$ wide and $31.6 \mathrm{~m}$ long. One bank of the channel can be partially removed to enable lateral erosion of the adjacent floodplain which consists of the same mobile bed material and longitudinal slope as the channel (Figure 2). Fixed banks delineate the widening area, representing hidden bank protection measures to limit lateral erosion. All data collected in the laboratory model were then upscaled with a Froude scale factor of $\lambda=30$. In prototype scale, the width of the initial channel is $26.8 \mathrm{~m}$, the widening can assume a maximum width of $107.4 \mathrm{~m}$, i.e. a widening ration of up to 4 , the length of the widening is $708 \mathrm{~m}$, i.e. long enough to be hydraulically effective (Hunzinger 1998), and the maximum widening area is $63,800 \mathrm{~m}^{2}$. 


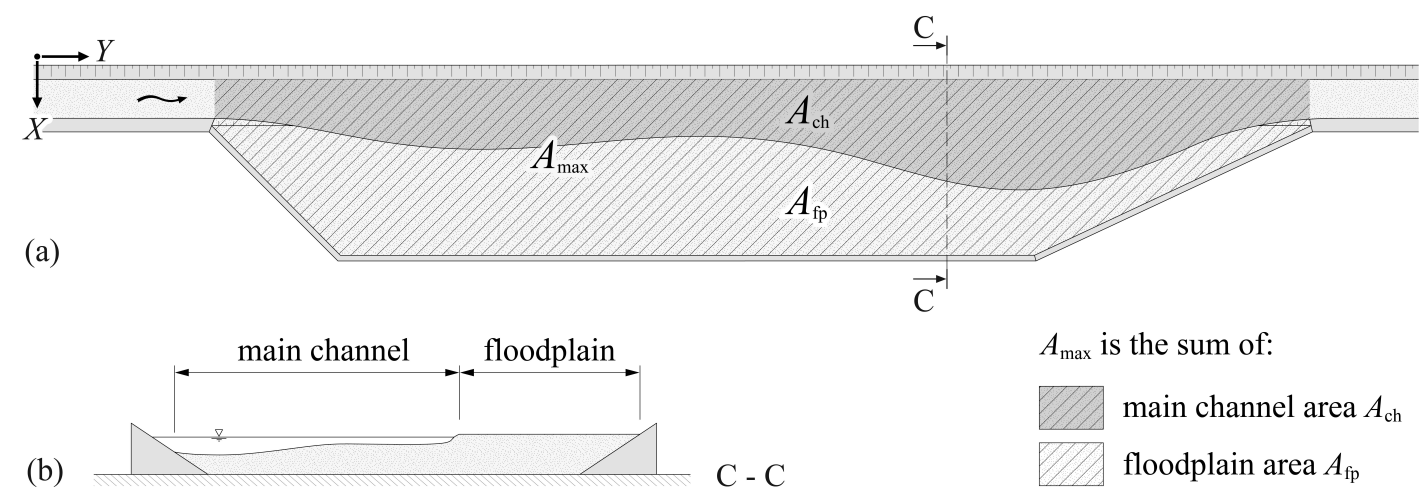

Figure 2. (a) Plan view and (b) cross-section of the laboratory experiment. The total widening area $A_{\text {max }}$ (striped) is composed of the main channel area $A_{\mathrm{ch}}$ (striped, dark gray) and the floodplain area $A_{\mathrm{fp}}$ (striped, light gray). The straight inlet and outlet sections do not contribute to any spatial analyses in this study.

Two hydraulic conditions were tested: (i) a steady bedforming discharge representing long-term exposure to a morphologically relevant discharge, hereafter referred to as BQ, and (ii) a hydrograph with a peak flow of approximately twice the bedforming discharge representing a single, moderately large flood event, hereafter referred to as FQ (see Table 1 for equivalent discharge values). In addition to the hydraulic conditions, the sediment supply at the inlet was varied to model sediment equilibrium and sediment deficit conditions. Three sediment supply levels (SSL) were applied: (i) $100 \%$ of the initial channel's transport capacity (TC), (ii) $60 \%$ of TC, and (iii) $20 \%$ of TC (hereafter referred to as SSL 100\%, SSL 60\%, and SSL 20\%). The tests with SSL $100 \%$ were run twice, while all other experiments being run once, providing a total of eight topographies (Table 2). For example, the topography FQ_60\% was obtained after a run with the FQ hydrograph as inflow and a sediment supply level of $60 \%$ TC. 
Table 2. Eight topographies obtained from laboratory experiments and the proportion of channel $\left(A_{\mathrm{ch}}\right)$ and floodplain area $\left(A_{\mathrm{fp}}\right)$ relative to the maximum widening area of $A_{\max }=63^{\prime} 800 \mathrm{~m}^{2}$. $A_{\mathrm{ch}} / A_{\max }=0.32$ corresponds to no widening of the initial channel. BQ denotes topographies developed under steady bedforming discharge and FQ under a flood hydrograph. The sediment supply level is indicated with the respective percentage. The sediment equilibrium tests were conducted twice.

\begin{tabular}{lcc}
\hline Topography & $A_{\mathrm{ch}} / A_{\max }$ & $A_{\mathrm{fp}} / A_{\max }$ \\
\hline BQ_100\%_1 & 0.51 & 0.49 \\
BQ_100\%_2 & 0.39 & 0.61 \\
BQ_60\% & 0.34 & 0.66 \\
BQ_20\% & 0.36 & 0.64 \\
\hline FQ_100\%_1 & 0.45 & 0.55 \\
FQ_100\%_2 & 0.39 & 0.61 \\
FQ_60\% & 0.43 & 0.57 \\
FQ_20\% & 0.42 & 0.58 \\
\hline
\end{tabular}

To reproduce initial channel topography, all tests commenced with SSL 100\% until an equilibrium between sediment input and output rates was established. In the sediment deficit tests, the SSL was then reduced to $60 \%$ TC or $20 \%$ TC, again until the sediment output rate equaled the input rate. A weak alternate bar pattern was formed in the straight channel for all SSL. The subsequent removal of the bank on one side enabled the lateral erosion processes to start. This phase was again continued until a transport equilibrium was established, and until the main channel width did not significantly change anymore. These phases were run with the steady bedforming discharge (BQ), before a single hydrograph (FQ) was run at the end of each series.

The flume was drained at 3-hour intervals and the dry bed topography recorded with a terrestrial laser scanner (Leica ScanStation P15) at a measurement accuracy of $\pm 0.06 \mathrm{~m}$ (upscaled value). A Digital Elevation Model (DEM) was subsequently obtained by interpolating the recorded point cloud onto a grid with a spacing of $0.3 \times 0.3 \mathrm{~m}$ (upscaled value). To separate the main channel area $A_{\mathrm{ch}}$ from the floodplain 
area $A_{\mathrm{fp}}$ (Figure 2) for each DEM, a plane of the type $P=a X+b Y+c$ was fitted to the floodplain. The plane was offset by $-2 D_{90}$ which is larger than or equal to the 99th percentile of the error between floodplain and fitted plane. The topography was then separated into patches below and above this dividing plane. If there were multiple patches below the plane, the largest patch was identified as the main channel with an area of $A_{\mathrm{ch}}$, and the remaining patches were assigned to the floodplain area $A_{\mathrm{fp}}$.

To identify zones of bed elevation change between two subsequent scans, the DEM of Difference (DoD) was obtained by subtracting the respective DEMs. As each DEM was recorded with an error of $\pm 0.06 \mathrm{~m}$ (upscaled value), the propagated error of the resulting DoD is $\left(0.06^{2}+0.06^{2}\right)^{0.5}=0.085 \mathrm{~m}$. Probabilistic thresholding with a Student's t-test and a confidence level of $95 \%$ was applied to identify areas of true change (Wheaton et al. 2010).

\subsection{Numerical model}

To collect hydraulic data with a high spatial resolution, numerical simulations were performed with BASEMENT (version 3.0), a freeware simulation tool for hydro- and morphodynamic modeling developed at VAW (Vetsch et al. 2020). We used the 2D model based on the depth-averaged shallow water equations for hydrodynamic simulations. Morphodynamic processes were not modeled, i.e. the bed was fixed for all simulations.

Every topography obtained in the laboratory experiments (Table 2) was transformed into a separate computational mesh with the BASEmesh plugin (BASEmesh 2020) for QGIS (QGIS.org 2020). To remove grain-scale roughness, the DEMs were first smoothed with the SAGA (Conrad et al. 2015) tool 'Mesh denoise' ( $T=0.7$, $n=20, v=50)$ integrated in QGIS. The tool is based on an algorithm by Sun et al. (2007), which removes noise without the loss of sharp topographic features (Stevenson et al. 2010). The filtered DEMs were subsequently interpolated onto an unstructured computational mesh with 238,935 elements. The element sizes are distributed homogeneously across the entire perimeter, with a minimum element size of $0.11 \mathrm{~m}^{2}$, a mean element size of $0.32 \mathrm{~m}^{2}$, and a maximum element size of $0.5 \mathrm{~m}^{2}$.

Uniform flow was assumed at both the upstream and the downstream model 
boundary. To robustly distinguish between wet and dry cells, we used a threshold of $h_{\text {dry }}=0.1 \mathrm{~m}$ (Toro 2001), which lies between the $D_{50}$ and $D_{90}$ of the bed material.

The numerical model was calibrated with longitudinal profiles of the water surface elevation in the laboratory experiment. The profiles were measured with an ultrasonic distance sensor mounted on a movable crossbeam above the flume. Each profile consists of 53 measurement points, $15 \mathrm{~m}$ apart (upscaled value). To provide the most accurate fit between measured water surface elevation and recorded topography, the profiles were recorded during the last $8.5 \mathrm{~min}$ of each experiment (upscaled value: $47 \mathrm{~min}$ ). We used the root mean square error (RMSE) to quantify the deviations between measured and calculated values. The only calibration parameter was the roughness, represented by the Strickler coefficient $k_{S t}\left(\mathrm{~m}^{1 / 3} / \mathrm{s}\right)$ and assumed to be equal for bed and banks. The calibration was carried out with the four BQ topographies (Table 2) and resulted in minimal RMSE values of 0.06-0.088 $\mathrm{m}$ for Strickler coefficients of $30-33 \mathrm{~m}^{1 / 3} / \mathrm{s}$. All subsequent simulations were carried out with $k_{S t}=31 \mathrm{~m}^{1 / 3} / \mathrm{s}$, which corresponds well to the Strickler coefficient range determined from $D_{90}$ with $k_{S t}=(21.1 \ldots 26) / D_{90}^{(1 / 6)}=28 \ldots 34 \mathrm{~m}^{1 / 3} / \mathrm{s}$ (Strickler 1923; Meyer-Peter and Müller 1948).

Steady state simulations were performed for every topography with discharges ranging from 40 to $320 \mathrm{~m}^{3} / \mathrm{s}$ in increments of $10 \mathrm{~m}^{3} / \mathrm{s}$, and the five characteristic discharges listed in Table 1 (34 discharges in total). Note that for some simulations, the simulated discharge is higher than the formative discharge of the topography, e.g. when a $\mathrm{H} Q_{30}$ discharge is run on any of the BQ topographies. This might lead to some unrealistic flow conditions, as the topography would constantly adjust to the imposed discharge under natural conditions. Nevertheless, the deviations are assumed to be small compared to the general trends in hydraulic variability that are observed when subjecting different topographies to a wide range of discharges (e.g. Reid et al. 2020).

\subsection{Data analysis}

From the numerical simulations, we extracted the wetted area $A_{\mathrm{w}}$ for each scenario (8 topographies with 29 discharges). Based on each DEM, $A_{\mathrm{w}}$ was divided into the wetted area belonging to the main channel $A_{\mathrm{w}, \mathrm{ch}}$ and the floodplain $A_{\mathrm{w}, \mathrm{fp}}$ (see Table 2 
for channel and floodplain areas). All spatial analyses are restricted to the widening area $A_{\max }=63,800 \mathrm{~m}^{2}$ (Figure 2).

From the wetted area, we calculated the shoreline length relative to the channel length $(\mathrm{km} / \mathrm{km})$ (Tockner and Stanford 2002). The shoreline length is a measure of complexity of the marginal zones and the lateral connectivity between aquatic, semiterrestrial, and terrestrial habitats (Ward et al. 1999). It is discharge-dependent and can assume values from $2 \mathrm{~km} / \mathrm{km}$ for straight channels up to $25 \mathrm{~km} / \mathrm{km}$ for braided morphologies such as the Tagliamento River in Italy (Tockner and Stanford 2002). We assume that the shoreline length can be used as a proxy for the availability of refugia in marginal zones (e.g. Rempel et al. 1999). To compute the shoreline length, the water depths obtained from the numerical simulations were interpolated onto a $0.3 \times 0.3 \mathrm{~m}$ grid as binary data $(1=$ wet, $0=$ dry $)$. To prevent overestimation of the shoreline length, the identified boundaries with a length $<100$ grid elements were removed and the remaining boundaries were smoothed with a filter of window length 21. All boundary lengths were then summed and divided by the streamwise length of the river widening.

A further result of the numerical simulations is the distribution of water depths, flow velocities, and bed shear stress values with high spatial resolution. Water depth and flow velocity are the basic descriptors of a flow field and can be used to assess the hydro-morphological conditions within the model perimeter. Here, we use the dimensionless hydro-morphological index of diversity (HMID, Gostner et al. 2013)

$$
H M I D=\left(1+\frac{\sigma_{v}}{\mu_{v}}\right)^{2} \cdot\left(1+\frac{\sigma_{h}}{\mu_{h}}\right)^{2}
$$

with the mean flow velocity $\mu_{v}(\mathrm{~m} / \mathrm{s})$, the standard deviation of the flow velocities $\sigma_{v}$ $(\mathrm{m} / \mathrm{s})$, the mean water depth $\mu_{h}(\mathrm{~m})$, and the standard deviation of the water depths $\sigma_{h}(\mathrm{~m})$ (Gostner et al. 2013). The higher the HMID the closer the hydro-morphological conditions are to natural conditions, independent of the specific morphology present, i.e. braiding or meandering. Gostner et al. (2013) introduced the classification (i) channelized and morphologically heavily altered for HMID $<5$, (ii) lightly modified 
with limited hydraulic variability for $5 \leq$ HMID $\leq 9$, and (iii) morphologically pristine for HMID $>9$. Note that the HMID was originally defined for mean flow conditions and its value is discharge-dependent.

Bed shear stresses describe the near-bed hydraulic forces acting on any organisms on the riverbed and are therefore relevant for refugia identification. They can also be interpreted as a proxy for potential bed-load transport. By comparing simulated bed shear stresses $\tau_{b}$ to a critical bed shear stress for the entrainment of a characteristic grain size, e.g. $\tau_{c, \mathrm{D} 50}$, potential bed-load transport zones may be identified. However, if the bed shear stresses are determined from a hydraulic simulation with homogeneous roughness, variations in surface roughness due to grain sorting are not considered. This simplification overlooks relevant morphodynamic processes such as riverbed patchiness, structuring, and armoring. Furthermore, this method does not consider the near-bed turbulent fluctuations of the velocity and pressure field that may locally modify grain mobility. Therefore, we used the aggradation and erosion zones identified from the DoDs obtained in the laboratory experiments to more reliably identify zones of bed elevation change and thus active bed-load transport. The wetted area $A_{w}$ was divided into the zones: (i) elevation change, (ii) no elevation change on floodplain, and (iii) no elevation change in channel. 


\section{Results}

\subsection{Floodplain inundation}

Simulated water depths for $\mathrm{H} Q_{1.5}$ and all eight topographies obtained in laboratory experiments (listed in Table 2) are shown in Figures 3 and 4. Under sediment equilibrium conditions (Figures 3a,b and 4a,b), topography and hydraulic conditions show a more complex pattern in comparison to sediment deficit conditions (Figures 3c,d and $4 \mathrm{c}, \mathrm{d})$. The floodplain is inundated and thus the wetted area $A_{\mathrm{w}}$ is significantly larger for sediment equilibrium cases in contrast to both the SSL $60 \%$ and $20 \%$ scenarios. Note that this is the case even though the proportion of main channel to floodplain area of BQ_100\%_2 and FQ_100\%_2 is closer to the sediment deficit scenarios than to BQ_100\%_1 and FQ_100\%_1 (Table 2). 


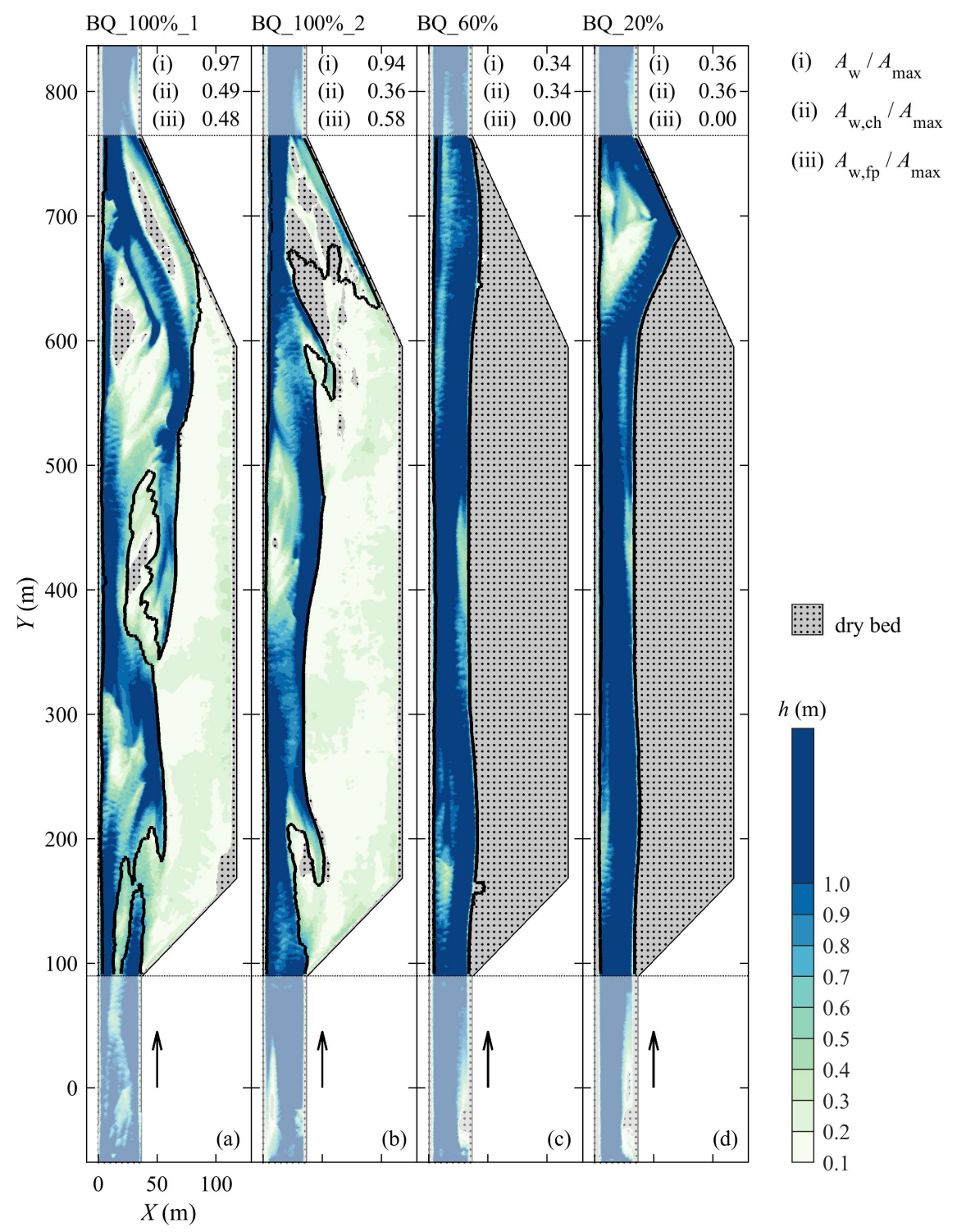

Figure 3. Simulated water depths for topographies (a) BQ_100\%_1, (b) BQ_100\%_2, (c) BQ_60\%, and (d) BQ_20\% and discharge $\mathrm{H} Q_{1.5}$. The proportion of (i) wetted area $A_{\mathrm{w}}$, (ii) wetted main channel area $A_{\mathrm{w}, \mathrm{ch}}$, and (iii) wetted floodplain area $A_{\mathrm{w}, \mathrm{fp}}$ to total widening area $A_{\max }$ is determined from the hydrodynamic simulations. The main channel area is defined as the area below the floodplain, and the inlet and outlet channel (white overlay) do not contribute to the reported areas. 


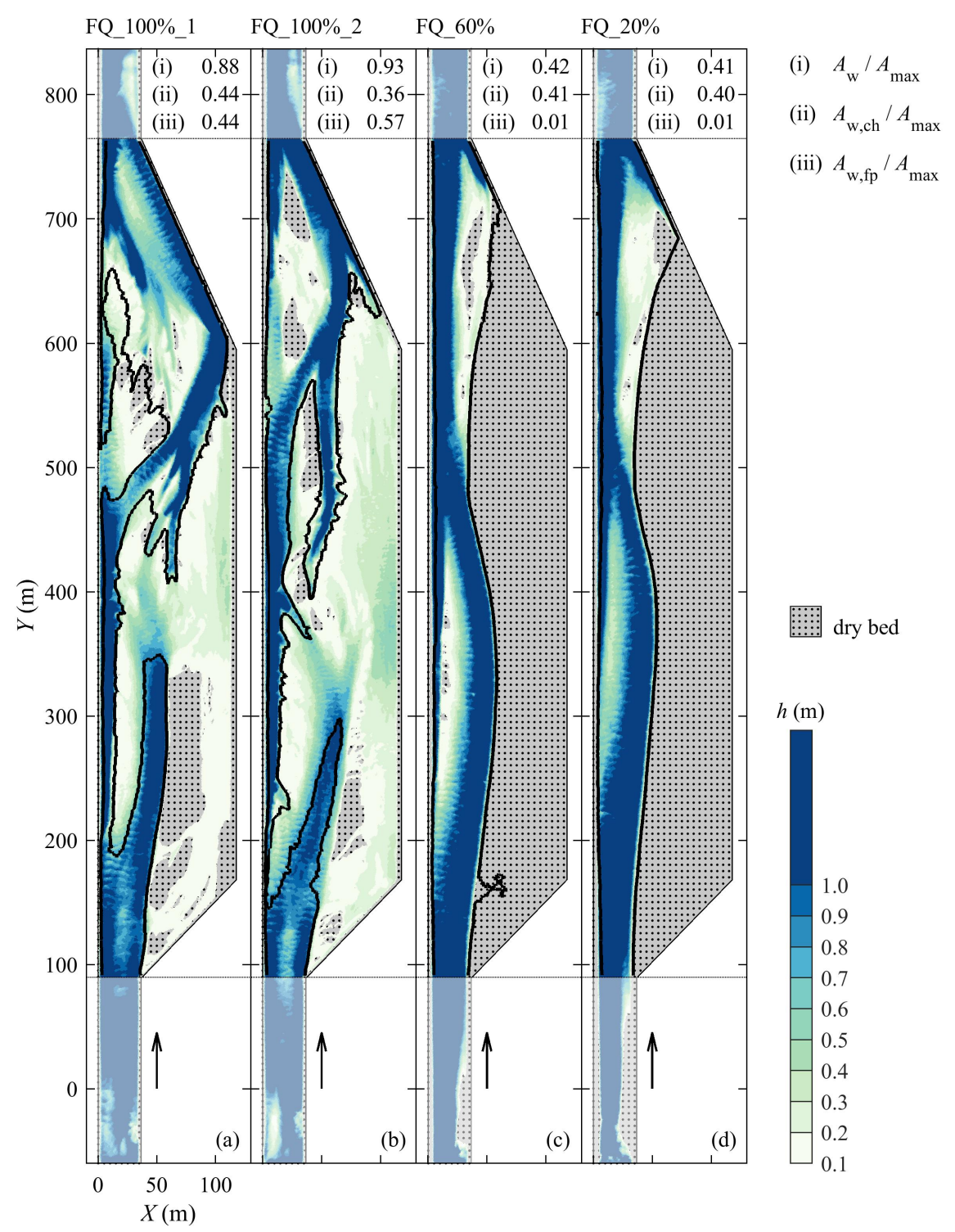

Figure 4. Simulated water depths for topographies (a) FQ_100\%_1, (b) FQ_100\%_2, (c) FQ_60\%, and (d) FQ_20\% and discharge $\mathrm{H} Q_{1.5}$. The proportion of (i) wetted area $A_{\mathrm{w}}$, (ii) wetted main channel area $A_{\mathrm{w}, \mathrm{ch}}$, and (iii) wetted floodplain area $A_{\mathrm{w}, \mathrm{fp}}$ to total widening area $A_{\max }$ is determined from the hydrodynamic simulations. The main channel area is defined as the area below the floodplain, and the inlet and outlet channel (white overlay) do not contribute to the reported areas.

To visualize the floodplain inundation process, Figure 5 displays the ratio of wetted area to total area $A_{\mathrm{w}} / A_{\max }$ for discharges between $40-320 \mathrm{~m}^{3} / \mathrm{s}$. The sediment equilibrium and deficit scenarios show distinctly different inundation dynamics visible as sharp increase of $A_{\mathrm{w}} / A_{\max }$ over a limited discharge range. For topographies developed under sediment equilibrium conditions (SSL 100\%), the floodplain is fully inundated 
at discharges around $150 \mathrm{~m}^{3} / \mathrm{s}$, for SSL $60 \%$ and $20 \%$ at discharges above $300 \mathrm{~m}^{3} / \mathrm{s}$. No significant differences are apparent between BQ (Figure 5a) and FQ topographies (Figure 5b), although the inundation process happens slightly more suddenly for BQ than for FQ topographies, especially for SSL $100 \%$.

Because the water depths on the inundated floodplain are shallow (Figures 3 and 4), $A_{\mathrm{w}}$ is potentially sensitive to the threshold $h_{\mathrm{dry}}=0.1 \mathrm{~m}$. However, a sensitivity analysis with $h_{\text {dry }}=0.05 \mathrm{~m}$ and $0.15 \mathrm{~m}$ showed no significant differences in the inundation process compared to $h_{\mathrm{dry}}=0.1 \mathrm{~m}$ (Supplementary Figure S1).
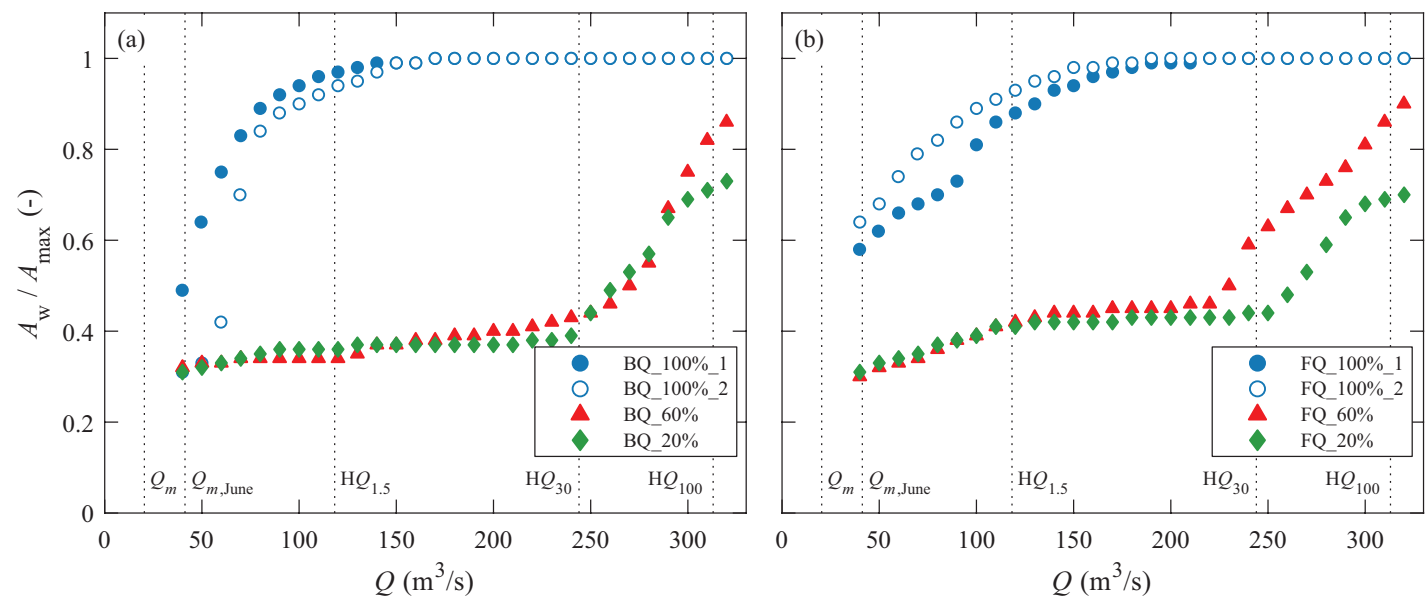

Figure 5. The ratio of wetted to total area $A_{\mathrm{w}} / A_{\max }$ for (a) four BQ and (b) four FQ topographies and a discharge range of $40-320 \mathrm{~m}^{3} / \mathrm{s}$ (29 discharges in total).

The inundation process is also reflected in the discharge-dependent shoreline length (Figure 6). The shoreline length is elevated and variable for the discharge range of partial floodplain inundation, and close to its minimum level of $2 \mathrm{~km} / \mathrm{km}$ for lower and higher discharges, i.e. a completely dry or wet floodplain. For example, shoreline length is 3-8 km/km for discharges below $150 \mathrm{~m}^{3} / \mathrm{s}$ for BQ_100\%_1 and BQ_100\%_2, whereas the minimum level of $2 \mathrm{~km} / \mathrm{km}$ is maintained for discharges $<\mathrm{H} Q_{30}$ for BQ_60\% and BQ_20\% (Figure 6a). 

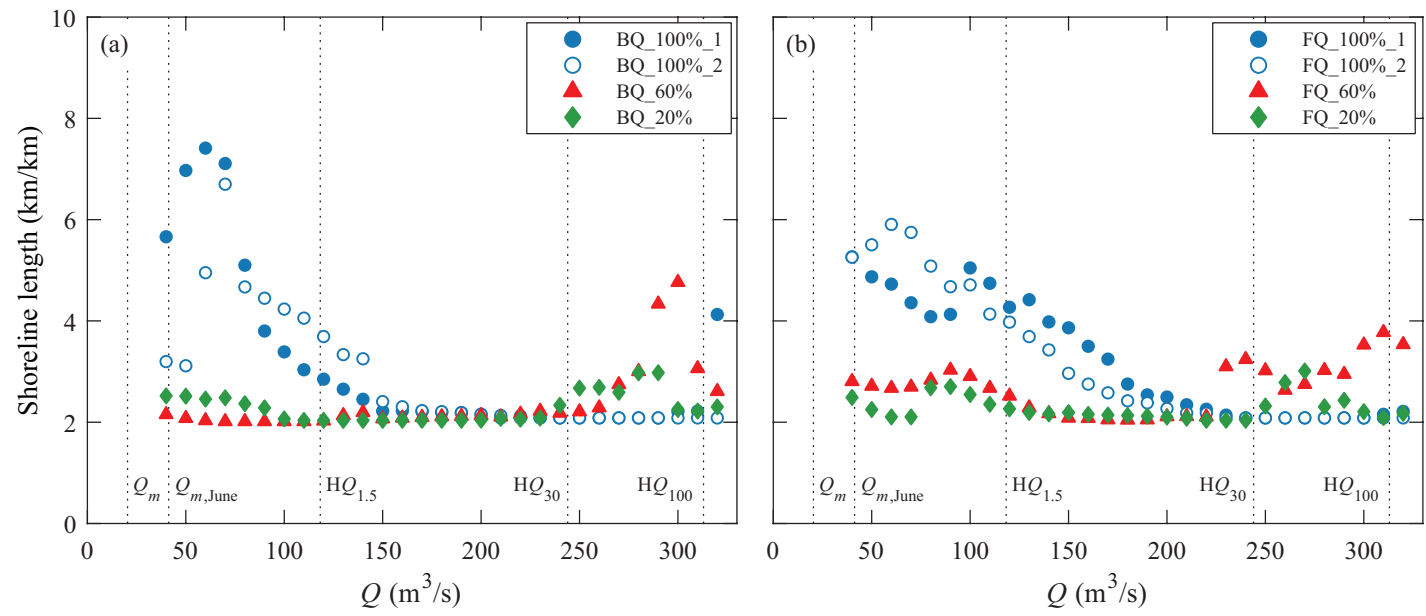

Figure 6. Shoreline length for (a) BQ and (b) FQ topographies and a discharge range of $40-320 \mathrm{~m}^{3} / \mathrm{s}$. The minimum value of the shoreline length is $2 \mathrm{~km} / \mathrm{km}$.

\subsection{Hydraulic variability}

Figures 3 and 4 show simulated water depths for a discharge of $\mathrm{H} Q_{1.5}$ and the separation between main channel and floodplain for the BQ and FQ topographies, respectively. Although the hydraulic forces, i.e. flow velocity and bed shear stress, are presumably more relevant for the refuge function, water depths are suitable to visualize the underlying topography and thus displayed here. For the corresponding visualization of flow velocities and bed shear stresses, see Supplementary Figures S2-S5.

Figures 3 and 4 indicate that the hydraulic variability is higher for sediment equilibrium conditions (SSL 100\%) as opposed to sediment deficit conditions (SSL 60\% and 20\%). Figure 7 quantifies the hydro-morphological diversity as HMID for a discharge range of $40-320 \mathrm{~m}^{3} / \mathrm{s}$. Maximum HMID values of 8-17 are attained for discharges $<\mathrm{H} Q_{30}$ under sediment equilibrium conditions and for discharge values $>\mathrm{H} Q_{30}$ under sediment deficit conditions. Minimum HMID values lie around 5 for sediment equilibrium conditions and $Q>\mathrm{H} Q_{30}$, and between 2 and 5 for sediment deficit conditions and $Q<\mathrm{H} Q_{30}$. The differences between the sediment supply levels are more pronounced for the BQ topographies than for the FQ topographies. 

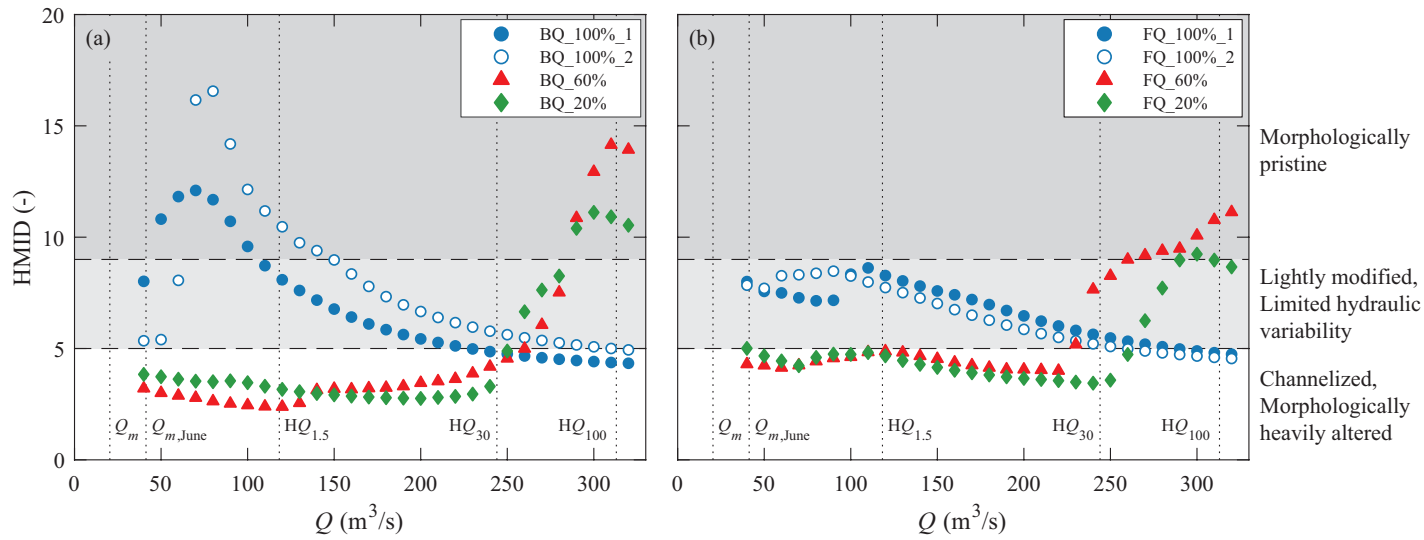

Figure 7. Hydro-morphological index of diversity (HMID) for the (a) BQ and (b) FQ topographies and a discharge range of $40-320 \mathrm{~m}^{3} / \mathrm{s}$ with the classification after Gostner et al. (2013). Note that the classification was originally developed for mean flow conditions.

For the five characteristic discharges listed in Table 1, the bed shear stress distributions are shown in Figures 8 and 9. Under sediment equilibrium conditions, the median bed shear stress slowly increases over the entire discharge range (Figures 8a,b and 9a,b). In contrast, the median increases more sharply for the SSL $60 \%$ and $20 \%$ scenarios, before it drops for $\mathrm{H} Q_{100}$ (Figures 8c,d and 9c,d).

The bed shear stress distribution and $A_{\mathrm{w}} / A_{\max }$ indicate that the floodplain is inundated at lower discharges under sediment equilibrium conditions compared to a sediment deficit (cf. Figure 5). The inundation leads to a high proportion of low bed shear stress areas, and a larger wetted area as indicated by the size of the gray area (e.g. Figure $8 \mathrm{a}$ at $\mathrm{H} Q_{1.5}$ ). Under sediment deficit conditions, only few low bed shear stress areas are available during flood events smaller than $\mathrm{H} Q_{100}$, and the total wetted area remains limited (Figures 8c,d and 9c,d). 

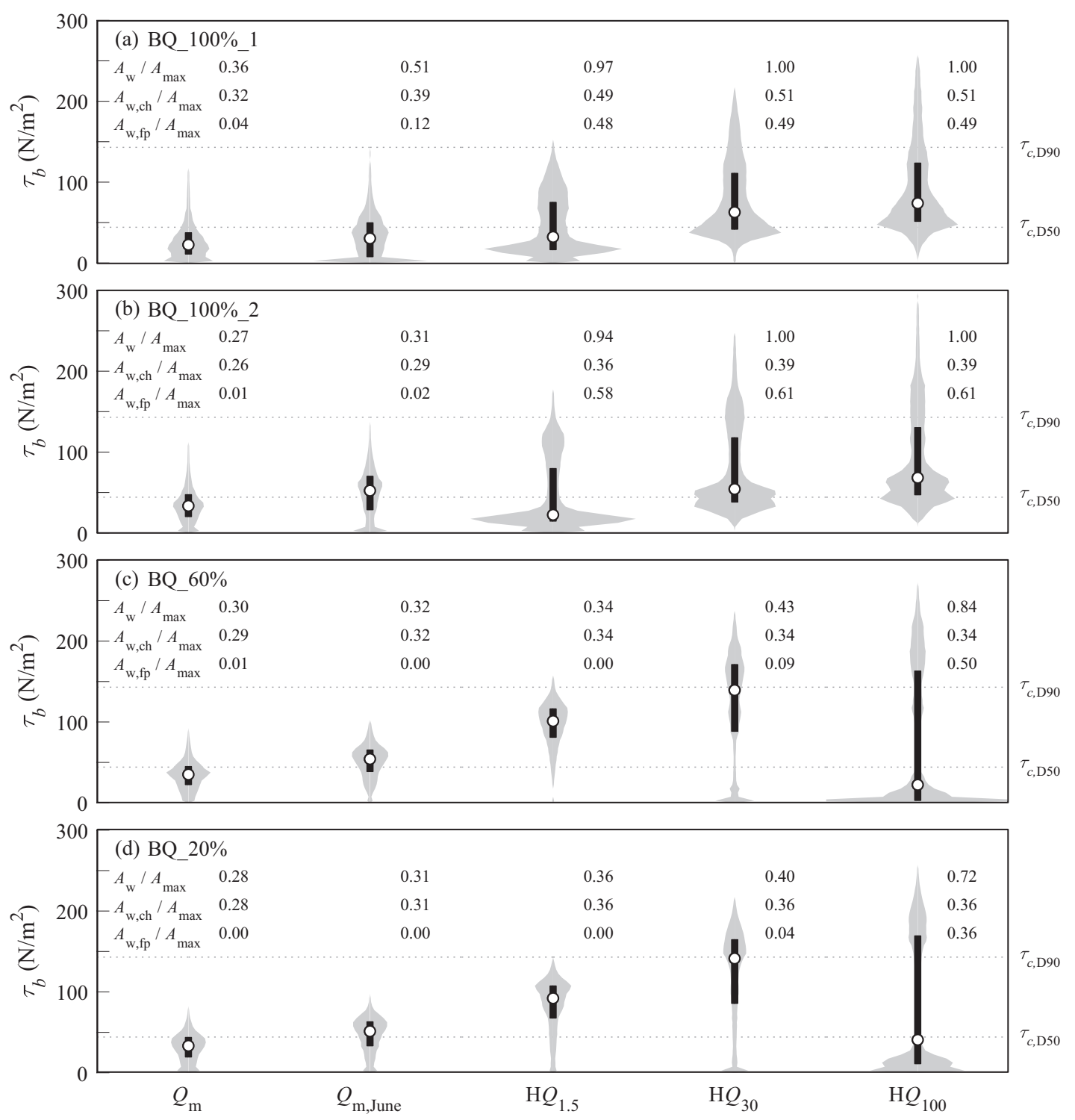

Figure 8. Bed shear stress distribution of the four BQ topographies (a-d) for five characteristic discharges $\left(Q_{m}\right.$ to $\left.\mathrm{H} Q_{100}\right)$. The gray area shows the distribution of bed shear stresses, the black bar the interquartile range, and the white circle the median value. The critical bed shear stress values for the entrainment of $D_{50}$ $\left(\tau_{c, \text { D50 }}\right)$ and $D_{90}\left(\tau_{c, \text { D90 }}\right)$ grains calculated with a dimensionless critical bed shear stress of $\theta_{c}=0.047$ are shown for comparison. The ratio of wetted area to total widening area $A_{\mathrm{w}} / A_{\max }$ and the respective proportion of main channel $A_{\mathrm{w}, \mathrm{ch}} / A_{\max }$ and floodplain $A_{\mathrm{w}, \mathrm{fp}} / A_{\max }$ are reported. 

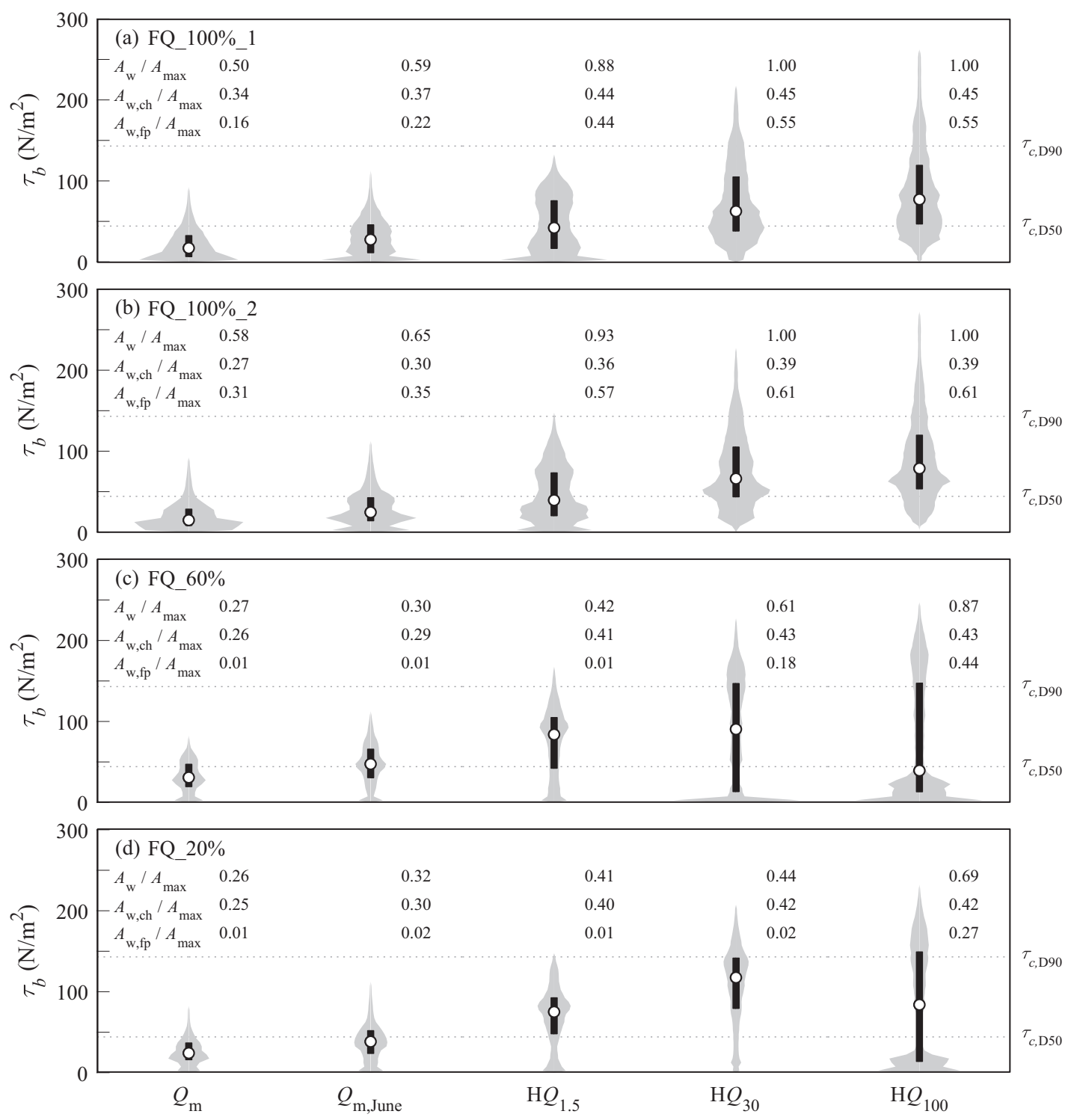

Figure 9. Bed hear stress distribution of the four FQ topographies (a-d) for five characteristic discharges $\left(Q_{m}\right.$ to $\left.\mathrm{H} Q_{100}\right)$. The gray area shows the distribution of bed shear stresses, the black bar the interquartile range, and the white circle the median value. The critical bed shear stress values for the entrainment of $D_{50}$ $\left(\tau_{c, \mathrm{D} 50}\right)$ and $D_{90}\left(\tau_{c, \mathrm{D} 90}\right)$ grains calculated with a dimensionless critical bed shear stress of $\theta_{c}=0.047$ are shown for comparison. The ratio of wetted area to total widening area $A_{\mathrm{w}} / A_{\max }$ and the respective proportion of main channel $A_{\mathrm{w}, \mathrm{ch}} / A_{\max }$ and floodplain $A_{\mathrm{w}, \mathrm{fp}} / A_{\max }$ are reported.

\subsection{Riverbed elevation change}

Figure 10 shows the relative frequencies of the bed shear stress distribution of the $\mathrm{BQ}$ topographies and their formative discharge $\mathrm{H} Q_{1.5}$. The inundated floodplain under 
sediment equilibrium conditions is clearly visible as a peak with $\tau_{b}<50 \mathrm{~N} / \mathrm{m}^{2}$ in Figures 10a and 10b. Most of the floodplain experiences no elevation change, except for a small part of very low bed shear stress areas (light gray and $\tau_{b}<10 \mathrm{~N} / \mathrm{m}^{2}$ ). These are most likely floodplain zones where a shallow layer of fines was deposited. In contrast, the limited occurrence of low bed shear stresses $\left(\tau_{b}<50 \mathrm{~N} / \mathrm{m}^{2}\right)$ for sediment deficit conditions (Figure 10c,d) indicates that the floodplain was not inundated at this discharge.

For $\tau_{b}>50 \mathrm{~N} / \mathrm{m}^{2}$, the bed shear stress distributions are rather similar between sediment equilibrium (Figures 10a,b) and sediment deficit conditions (Figures 10c,d), although the distribution is slightly flatter in Figures 10a and b. However, the relative frequency of the wetted area experiencing bed elevation change is significantly higher for sediment equilibrium and there is, therefore, an extensive zone of active bed-load transport in the main channel. In contrast, most of the wetted area experienced no bed elevation change under sediment deficit conditions (Figures 10c,d). There might still be bed-load transport across such a zone without bed elevation change (no net change). But due to the low sediment supply and the armored bed surface, the active bed-load transport zone is likely very limited (cf. Dietrich et al. 1989). 

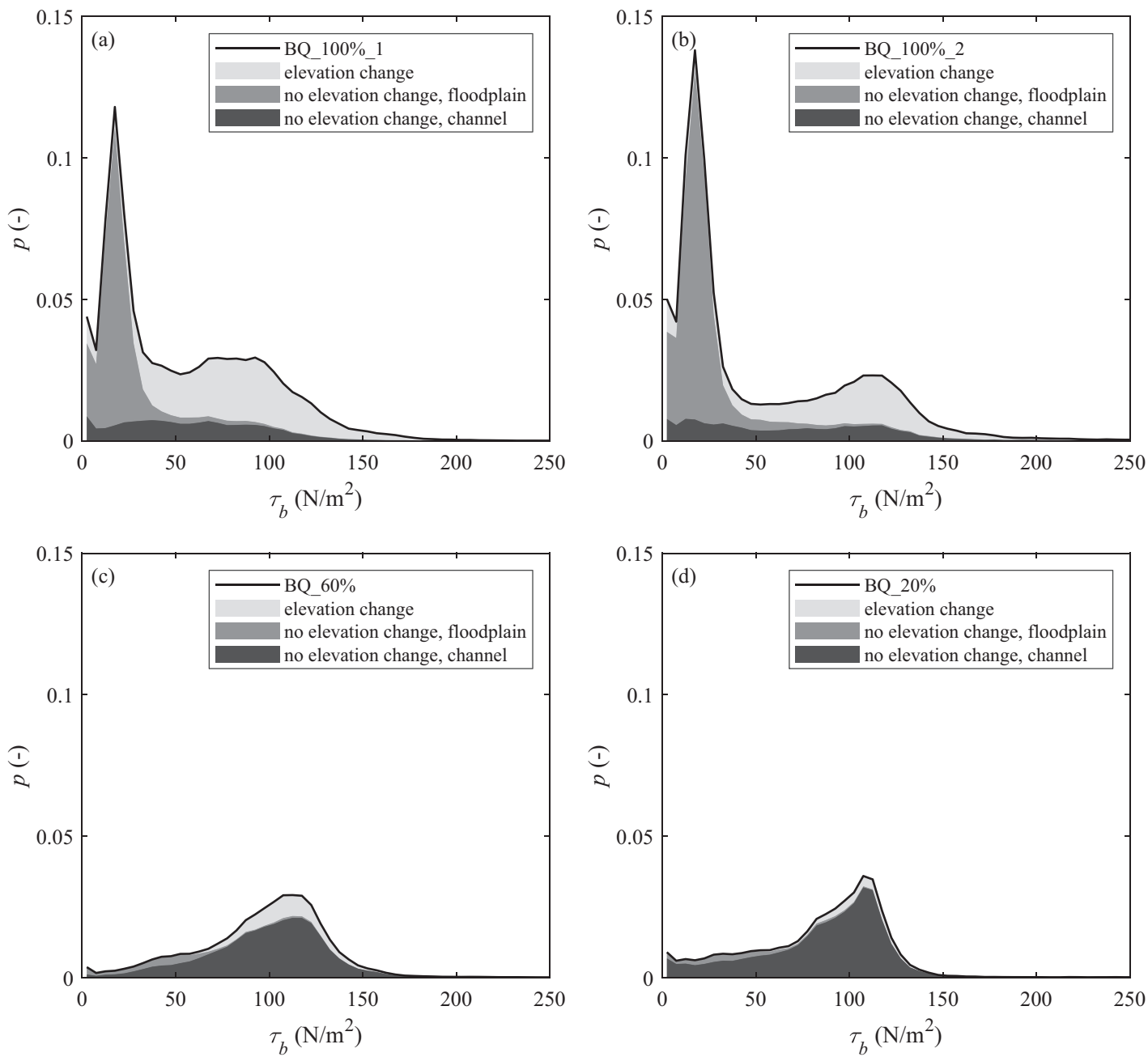

Figure 10. Relative frequency $p$ of bed shear stress distributions and the partition into areas with and without elevation change for (a) BQ_100\%_1, (b) BQ_100\%_2, (c) BQ_60\%, and (d) BQ_20\% and the bedforming discharge $\mathrm{H} Q_{1.5}$. The area with elevation change (light gray) was determined from a 3-hour interval in the laboratory experiment. 


\section{Discussion}

This study sought to relate refugia availability for mobile aquatic organisms in a dynamic river widening to the underlying process of sediment transport, which may have contrasting impacts regarding refugia availability. Sediment transport is itself a disturbance causing scour and fill (e.g. Townsend et al. 1997; Effenberger et al. 2006; Czuba et al. 2018), however it is also a key driver of morphodynamics and habitat variability (e.g. Reid et al. 2020) which is considered a prerequisite for the persistence of low-impact habitats during flood events (Sedell et al. 1990).

\subsection{Interaction of sediment supply and hydro-morphological complexity}

The maximum shoreline lengths observed here are in the range of $5-8 \mathrm{~km} / \mathrm{km}$ for sediment equilibrium conditions and $Q<\mathrm{H} Q_{30}$, and $3-5 \mathrm{~km} / \mathrm{km}$ for sediment deficit conditions and $Q>\mathrm{H} Q_{30}$. These values correspond to the lower end of the range 5$15 \mathrm{~km} / \mathrm{km}$ reported for a constrained but not channelized reach of the Danube River in Austria (Tockner and Stanford 2002). In contrast, a natural river, such as the Tagliamento River in Italy, reaches shoreline lengths of $25 \mathrm{~km} / \mathrm{km}$ (Tockner and Stanford 2002). While the shoreline length of the Danube River displays high dependence on discharge similar to this study, the Tagliamento River maintains consistently high shoreline lengths with the exception of very low and very high discharges (van der Nat et al. 2002). Assuming that a higher shoreline length results in more potential refuge areas in the marginal zones (e.g. Rempel et al. 1999), dynamic river widenings developed under sediment equilibrium conditions show a higher refuge potential compared to sediment deficit scenarios. However, due to the limited length and width of river widenings, the attainable shoreline lengths remain limited.

While this general outcome is reasonable, the absolute shoreline length values must be treated with caution. Although the numerical model has a high spatial resolution, it cannot represent the full complexity of marginal zones with crevices, indentations, etc., and absolute values of shoreline length generally depend on the observation scale. Furthermore, the floodplain in the laboratory experiment is unrealistically flat. This causes the shoreline length to drop to its minimum value of $2 \mathrm{~km} / \mathrm{km}$ once the flood- 
plain is completely inundated. Although the shoreline length will likely decrease for elevated discharges, it will not drop to the minimum value in case the floodplain is more structured, for example with patches of vegetation (Tockner and Stanford 2002).

The HMID values follow a similar trend as the shoreline length, with higher values and thus higher hydro-morphological diversity for sediment equilibrium conditions and $Q<\mathrm{H} Q_{30}$ and a reversal for $Q>\mathrm{H} Q_{30}$, therefore capturing the different floodplain inundation processes. However, at $\mathrm{H} Q_{30}$, equal HMID values of 4-6 result for the BQ topographies under both sediment equilibrium and deficit conditions (Figure 7a), implying that their respective flow fields are equally diverse. However, Figure 3 shows that for sediment equilibrium and $\mathrm{H} Q_{1.5}$, the water depth distribution consists of smaller patches and exhibits a more complex configuration than under sediment deficit conditions, and similar differences can be expected for $\mathrm{H} Q_{30}$. The reason for equal HMID despite apparent differences in the respective flow fields is that the HMID is a statistical bulk value to quantify hydro-morphological diversity (Eq. 1). It does not, however, express the spatial arrangement of hydraulic patches (Gostner et al. 2013) which makes it suitable to measure the variability, but not the complexity of a hydraulic habitat mosaic.

For discharges up to $\mathrm{H} Q_{30}$, both the shoreline length and HMID values are higher under sediment equilibrium compared to sediment deficit conditions. For discharges $>\mathrm{H} Q_{30}$ the relationship is inverse. Assuming that potentially more refugia are available in morphologically and hydraulically complex reaches (e.g. Pearsons et al. 1992; Gjerløv et al. 2003), both metrics imply higher refugia availability under sediment equilibrium conditions and discharges up to $\mathrm{H} Q_{30}$. This dynamic is closely linked to the lateral channel-floodplain connectivity. Under sediment equilibrium conditions, stronger bed aggradation in the widened main channel led to reduced elevation differences between the main channel and the floodplain and, therefore, the floodplain is inundated at lower discharges (e.g. Hohensinner et al. 2003). Conversely, the incision of the main channel relative to the floodplain under sediment deficit conditions prevents the floodplain inundation except for high discharges (e.g. Surian and Rinaldi 2003).

However, increased lateral connectivity is only one of many factors that likely lead to a higher refugia availability in sediment equilibrium conditions. Low bed shear stress 
zones that persist during high discharges also provide potentially valuable refugia (e.g. Lancaster and Hildrew 1993; Winterbottom et al. 1997). Lancaster and Hildrew (1993) distinguish three types of bed shear stress shifts in response to increasing discharge: type I from unimodal skewed to bimodal, type II from unimodal skewed to unimodal bell-shaped, and type III from bimodal to unimodal bell-shaped (see Figure 7 in Lancaster and Hildrew 1993). They concluded that a type I shift in bed shear stresses holds the highest potential for refugia, because low bed shear stress zones persist throughout the discharge range associated with the main channel being most affected by a disturbance event (Lepori and Hjerdt 2006). In this study, the conditions under sediment equilibrium correspond to a type I shift which is mainly associated with the inundation of the floodplain activating an extensive area of shallow water depths, slow flow velocities, and low bed shear stress zones. Conversely, the sediment deficit conditions resemble a type II shift with a narrow distribution of ever increasing bed shear stresses except for $\mathrm{H} Q_{100}$, when the floodplain is inundated and the distribution also resembles type I. The stronger increase of bed shear stresses under sediment deficit conditions can be explained by topographic characteristics. The homogeneous main channel that was preserved under sediment deficient conditions effectively concentrates the flow and leads to higher bed shear stresses with a more narrow distribution in comparison to sediment equilibrium conditions (e.g. Negishi et al. 2002; Czuba et al. 2018). Some benthic organisms may be able to move to the subsurface zone, but the refuge function of the hyporheic zone is highly variable (e.g. Dole-Olivier et al. 1997; Stubbington 2012). It can be concluded that the hydro-morphological conditions developed under sediment deficit conditions are less likely to provide suitable flood refugia.

\subsection{The floodplain as a refuge}

Under sediment equilibrium conditions, the floodplain is inundated at comparably low discharges $\left(Q_{m, \text { June }}-\mathrm{H} Q_{1.5}\right)$, suggesting that its shallow and slow flowing zones are readily accessible as refuge. But does the floodplain really assume refuge function? Schwartz and Herricks (2005) reported fish moving into the floodplain during high discharges and the same has been observed for macroinvertebrates (e.g. Negishi et al. 2002). However, the organisms must also be able to successfully return to the 
main channel once the flood receeds. A field study on macroinvertebrate refugia in a New Zealand stream investigated the refuge function of the floodplain by differentiating between the floodplain acting as a temporary shelter versus a permanent refuge (Matthaei and Townsend 2000). According to their study, the conditions in the main channel during the falling limb of the hydrograph are essential, i.e. when the flow retreats from the floodplain and organisms return back to the main channel. Stranding on the drying floodplain does not seem to be a significant risk to macroinvertebrates (Matthaei and Townsend 2000) or fish (Mannes et al. 2008). However, if hydraulic conditions in the main channel remain unfavorable when the organisms return, i.e. with high bed shear stresses and active bed-load transport, the temporary shelter on the floodplain does not offer any advantage regarding the persistence of organisms.

From the floodplain inundation dynamics, it was determined that the flow retreats from the floodplain below discharges of $Q_{m, \text { June }}-\mathrm{H} Q_{1.5}$ for sediment equilibrium conditions which corresponds to median bed shear stresses of $23-53 \mathrm{~N} / \mathrm{m}^{2}$ being present in the main channel. In contrast, the water almost entirely retreats from the floodplain around $\mathrm{HQ}_{30}$ under sediment deficit conditions, with median bed shear stresses of 90$140 \mathrm{~N} / \mathrm{m}^{2}$ in the channel, thus presenting a higher risk for displacement. Note that the bed shear stresses determined from a two-dimensional hydrodynamic model cannot accurately represent the detailed near-bed flow field (Rice et al. 2007), but rather allow comparison of the relative magnitudes of the hydraulic forces.

Another process to consider when evaluating floodplain refugia availability is bedload transport activity in the main channel upon floodplain drying (Matthaei and Townsend 2000). Under sediment equilibrium conditions, the active bed-load transport zone determined from the laboratory experiments at $\mathrm{H} Q_{1.5}$ is more extensive than under sediment deficit conditions (e.g. Dietrich et al. 1989; Nelson et al. 2009). Consequently, organisms returning from the floodplain to the main channel under sediment equilibrium conditions are possibly subjected to destructive bed-load transport (e.g. Effenberger et al. 2006; Matthaei and Townsend 2000). However, even at $\mathrm{H} Q_{1.5}$, there is a significant portion of low bed shear stress areas without bed elevation change in the channel (Figures 10a,b). Considering that the floodplain only completely dries up for discharges below $Q_{m \text {,June }}$ and bed-load transport activity will have decreased fur- 
ther, we can therefore assume that under sediment equilibrium conditions, organisms retreating from the floodplain will find plenty of potentially suitable habitat patches in the main channel.

\subsection{Refugia availability versus use}

The results of this study illustrate that a dynamic river widening developed under sediment equilibrium conditions has a higher refuge potential compared to sediment deficit conditions. However, the availability of refugia does not necessarily imply positive effects on the biota (cf. Palmer et al. 2010). The use of refugia by aquatic organisms is dependent on a variety of factors that this study does not investigate. Organism characteristics such as their mobility (e.g. Williams and Hynes 1976; Rice et al. 2007) and their body size versus the spatial dimensions of the refuge (e.g. Lancaster 2000; Schwartz and Herricks 2005; Mathers et al. 2019) play an important role. Organisms seek out different refugia associated with varying suitability under differing discharge regimes. Sculpins are for example especially susceptible to scouring events as they hide in the interstitial pore spaces (Swanson et al. 1998). This refuge may therefore be suitable below a critical discharge, above which it is destroyed instantaneously. The higher the flood severity, the more valuable large-scale refugia, such as tributaries and floodplains, become (Sedell et al. 1990).

The spatial configuration and hierarchy of refugia was not considered in this study, but may also have important implications for their use (e.g. Sedell et al. 1990; Lancaster and Belyea 1997). For example, the proximity and accessibility of a refuge to the residential habitat of an organism is crucial regarding its energy expenditure (e.g. Weber et al. 2013; Sueyoshi et al. 2014). In the setting studied here, this means that possibly only the margin areas close to the main channel may be used as a refuge and not the entire floodplain. This effect was observed by Matthaei and Townsend (2000) where floodplain areas close to the main channel were more likely to serve as a refuge compared to a backwater channel further away. 


\subsection{Implications for management}

The results presented here show no substantial deviations between topographies developed during steady bedforming flow (BQ) and during a flood event (FQ). This indicates that refugia availability in dynamic river widenings may be fairly independent of specific hydrological events and far more influenced by the sediment supply conditions. All results exhibit significant differences between sediment equilibrium and sediment deficit conditions, whereas the tested degrees of sediment deficit (60\% or $20 \%)$ do not seem to be profoundly relevant to the outcome. For the investigated cases, sediment deficit leads to channel incision which disconnects the main channel from the floodplain. The sediment deficit also reduces the tendency for local erosion and deposition of material throughout the reach thus weakening lateral erosion. The result is a distinctly different morphology and degree of lateral connectivity which both negatively impact refugia availability. Our results therefore suggest that an equilibrium sediment supply clearly favors refugia availability in a dynamic river widening. However, the available lab data do not reveal a transition for the degree of sediment deficit at which negative effects start to prevail; this requires further and systematic lab experiments.

This study provides an example of the conflicts that may arise if restoration measures do not target large-scale ecosystem processes but instead focus on habitat structure on a reach scale (e.g. Beechie et al. 2010; Polvi et al. 2020). In order for dynamic river widening to be an effective restoration measure, pressures on a larger scale such as impaired sediment and flow regimes (e.g. Vanzo et al. 2016), insufficient water quality, or land use changes must be addressed and, if possible, restored concurrently (Kondolf et al. 2006). Mitigation measures for sediment supply include various structural (e.g. sediment bypass tunnels), operational (e.g. reservoir drawdown), and replenishment measures (Kondolf et al. 2014). In Switzerland, a concerted effort to mitigate the effects of channel degradation, fish migration barriers, sediment deficit, and hydropeaking is ongoing (Bammatter et al. 2015). Regarding the interruption of sediment continuity, approximately five hundred hydropower dams and weirs as well as other structures must be altered to improve sediment connectivity. This opens opportunities for downstream channel restoration measures, such as dynamic river widenings, to fulfill their ecological potential, for example by providing suitable flood refugia. 


\section{Conclusions}

Our results indicate that dynamic river widenings exhibit higher morphodynamic activity, greater hydro-morphological diversity, and a stronger lateral connectivity under equilibrium sediment supply compared to sediment deficit conditions. Low bed shear stresses are preserved during elevated discharge thus potentially providing more suitable refugia to mobile aquatic organisms. The positive effects of bed-load transport prevail, even though it is itself a disturbing force. In contrast, sediment deficit conditions lead to impoverished hydro-morphological conditions and the floodplain is unavailable, owing to incision, as refuge due to channel-floodplain disconnection. These findings imply that the potential ecological benefits of dynamic river widenings in subalpine gravel-bed rivers are strongly dependent on the sediment supply level. If a river widening is planned in a reach with a sediment deficit, additional measures such as the placement of structuring elements (e.g. groins, engineered log jams) may be necessary to improve refugia availability and increase the resistance and resilience of stream communities. To generalize the relation between sediment supply and refugia availability in the context of river restoration, further studies on different river systems and restoration methods are necessary.

The ecological assessment of restoration measures, such as dynamic river widenings, should not be limited to the investigation of flood refugia, but also consider the impacts of other disturbance events, especially droughts (e.g. Lake 2000; Wood et al. 2010). Due to climate warming, dry periods are becoming more frequent in many regions and the investigation of habitat fragmentation gains in importance (e.g. Vander Vorste et al. 2020). If dynamic river widening leads to large open spaces without shade and with shallow water depths, the restoration measure may not provide suitable conditions for biota in low discharge situations. It is therefore crucial to further investigate the impacts of all relevant types of disturbance events on biota in the context of river restoration. 


\section{Acknowledgements}

This study is part of the interdisciplinary research program Hydraulic engineering and ecology in its fourth project phase Riverscapes - Sediment Dynamics and Lateral Connectivity. The research program is funded by the Swiss Federal Office for the Environment (FOEN), the Swiss Federal Institute of Aquatic Science and Technology (Eawag), the Swiss Federal Institute for Forest, Snow and Landscape Research (WSL), the Platform of Hydraulic Constructions (PL-LCH) at EPFL Lausanne, and the Laboratory of Hydraulics, Hydrology and Glaciology (VAW) at ETH Zurich. The authors would like to thank Barbara Stocker (master student) and the technical staff at VAW for their valuable assistance with the experimental study. We wish to thank two anonymous reviewers for their helpful comments on the manuscript.

\section{Disclosure statement}

No potential conflict of interest was reported by the authors.

\section{Funding}

The first and second author are financially supported by the Swiss Federal Office for the Environment (FOEN), Grant 16.0113.PJ / P501-1050.

\section{ORCID}

Cristina Rachelly https://orcid.org/0000-0003-3147-3807

Kate L. Mathers https://orcid.org/0000-0003-3741-1439

Volker Weitbrecht https://orcid.org/0000-0003-3008-5167

Robert M. Boes https://orcid.org/0000-0002-0319-976X

David F. Vetsch https://orcid.org/0000-0003-3293-5831 


\section{References}

Bammatter L, Baumgartner M, Greuter L, Haertel-Borer S, Huber Gysi M, Nitsche M, Thomas G. 2015. Renaturierung der Schweizer Gewässer: Die Sanierungsplane der Kantone ab 2015 [Swiss river restoration: The cantonal restoration plans from 2015]. Federal Office for the Environment, Bern, Switzerland. 1-13 [in German].

BASEmesh. 2020. BASEmesh - tool for generation of computational meshes for numerical software BASEMENT. Laboratory of Hydraulics, Hydrology and Glaciology (VAW), ETH Zurich, Switzerland. https://basement.ethz.ch/download/tools/basemesh.html

Bernhardt ES, Palmer MA, Allan JD, Alexander G, Barnas K, Brooks S, Carr J, Clayton S, Dahm C, Follstad-Shah J, Galat D, Gloss S, Goodwin P, Hart D, Hassett B, Jenkinson R, Kath S, Kondolf GM, Lake PS, Lave R, Meyer JL, O’Donnell TK, Pagano L, Powell B, Sudduth E. 2005. Synthesizing U.S. River Restoration Efforts. Science. 308(5722):636-637.

Beechie TJ, Sear DA, Olden JD, Pess GR, Buffington JM, Moir H, Roni P, Pollock MM. 2010. Process-based Principles for Restoring River Ecosystems. BioScience. 60(3):209-222.

Castro JM, Thorne CR. 2019. The stream evolution triangle: Integrating geology, hydrology, and biology. River Res Applic. 35:315-326.

Conrad O, Bechtel B, Bock M, Dietrich H, Fischer E, Gerlitz L, Wehberg J, Wichmann V, Böhner J. 2015. System for Automated Geoscientific Analyses (SAGA) v. 2.1.4. Geosci Model Dev., 8, 1991-2007.

Czuba CR, Czuba JA, Magirl CS, Gendaszek AS, Konrad CP. 2018. Effect of river confinement on depth and spatial extent of bed disturbance affecting salmon redds. J Ecohydraulics. $3(1): 4-17$.

Dietrich W, Kirchner J, Ikeda H, Iseya F. 1989. Sediment supply and the development of the coarse surface layer in gravel-bedded rivers. Nature. 340:215-217.

Dole-Olivier MJ, Marmonier P, Beffy JL. 1997. Response of invertebrates to lotic disturbance: is the hypotheic zone a patchy refugium? Freshwater Biol. 37:257-276.

Dudgeon D, Arthington AH, Gessner MO, Kawabata Z-I, Knowler DJ, Lévêque C, Naiman RJ, Prieur-Richard A-H, Soto D, Stiassny MLJ, Sullivan CA. 2006. Freshwater biodiversity: importance, threats, status and conservation challenges. Biol Rev. 81:163-182.

Effenberger M, Sailer G, Townsend CR, Matthaei CD. 2006. Local disturbance history and habitat parameters influence the microdistribution of stream invertebrates. Freshwater Biol. 51:312-332.

FOEN: Federal Office for the Environment. 2014. Generalised background map for 
the representation of hydrological data. https://opendata.swiss/en/dataset/generalisiertehintergrundkarte-zur-darstellung-hydrologischer-daten

FOEN: Federal Office for the Environment. 2015. Kander River, Switzerland. 2014/2015 topographic survey. https://www.bafu.admin.ch/bafu/de/home/themen/naturgefahren/fachinformationen/naturgefahrensituationund-raumnutzung/gefahrengrundlagen/naturgefahren-flussvermessung.html

FOEN: Federal Office for the Environment. 2017. Kander River, Switzerland. Hydrometric data of the station EDV 2469: Kander - Hondrich, data series 1981-2017. https://www.hydrodaten.admin.ch/de/2469.html

Garcia Lugo GA, Bertoldi W, Henshaw AJ, Gurnell AM. 2015. The effect of lateral confinement on gravel bed river morphology. Water Resour Res. 51:7145-7158.

Gjerløv C, Hildrew AG, Jones JI. 2003. Mobility of stream invertebrates in relation to disturbance and refugia: a test of habitat templet theory. J N Am Benthol Soc. 22(2):207-223.

Gostner W, Alp M, Schleiss AJ, Robinson CT. (2013). The hydro-morphological index of diversity: a tool for describing habitat heterogeneity in river engineering projects. Hydrobiologia. 712(1):43-60.

Gurnell AM, Piégay H, Swanson FJ, Gregory SV. 2002. Large wood and fluvial processes. Freshwater Biol. 47(4):601-619.

Habersack H, Piégay H. 2007. River restoration in the Alps and their surroundings: past experience and future challenges. In: Habersack H, Piégay H, Rinaldi M, editors. Developments in Earth Surface Processes, Elsevier. 11:703-735.

Hohensinner S, Habersack H, Jungwirth M, Zauner G. 2003. Reconstruction of the characteristics of a natural alluvial river-floodplain system and hydromorphological changes following human modifications: the Danube River (1812-1991). River Res Applic. 20:25-41.

Hohensinner S, Jungwirth M, Muhar S, Schmutz S. 2011. Spatio-temporal habitat dynamics in a changing Danube River landscape 1812-2006. River Res Applic. 27:939-955.

Hunzinger L. 1998. Flussaufweitungen - Morphologie, Geschiebehaushalt und Grundsätze zur Bemessung [River widenings - morphology, bed-load balance, and design guidelines]. VAW-Mitteilung 159 (HE Minor, ed.). Laboratory of Hydraulics, Hydrology and Glaciology (VAW), ETH Zurich, Switzerland [in German].

Huwiler A, Stocker B. 2019. Numerische Modellierung und Habitatcharakerisierung in einer Flussaufweitung [Numerical modeling and characterization of habitats in a river widening] [master's thesis]. Laboratory of Hydraulics, Hydrology and Glaciology (VAW), ETH Zurich, 
Switzerland [in German].

Kondolf G. 1997. PROFILE: Hungry Water: Effects of Dams and Gravel Mining on River Channels. Environ Manage. 21:533-551.

Kondolf GM, Boulton AJ, O’Daniel S, Poole GC, Rahel FJ, Stanley EH, Wohl E, Bång A, Carlstrom J, Cristoni C, Huber H, Koljonen S, Louhi P, Nakamura K. 2006. Process-based ecological river restoration: visualizing three-dimensional connectivity and dynamic vectors to recover lost linkages. Ecol Soc. 11(2):5.

Kondolf GM, Gao Y, Annandale GW, Morris GL, Jiang E, Zhang J, Cao Y, Carling P, Fu K, Guo Q, Hotchkiss R, Peteuil C, Sumi T, Wang HW, Wang Z, Wei Z, Wu B, Wu C, Yan CT. 2014. Sustainable sediment management in reservoirs and regulated rivers: Experiences from five continents. Earth's Future. 2.

Lake PS. 2000. Disturbance, patchiness, and diversity in streams. J N Am Benthol Soc. $19(4): 573-592$.

Lancaster J. 2000. Geometric scaling of microhabitat patches and their efficacy as refugia during disturbance. J Anim Ecol. 69:442-457.

Lancaster J, Belyea LR. 1997. Nested hierarchies and scale-dependence of mechanisms of flow refugium use. J N Am Benthol Soc. 16(1):221-238.

Lancaster J, Hildrew AG. 1993. Characterizing In-stream Flow Refugia. Can J Fish Aquat Sci. 50:1663-1675.

Lepori F, Hjerdt N. 2006. Disturbance and Aquatic Biodiversity: Reconciling Contrasting Views. BioScience. 56(10):809-818.

Mannes S, Robinson CT, Uehlinger U, Scheurer T, Ortlepp J, Mürle U, Molinari P. 2008. Ecological effects of a long-term flood program in a flow-regulated river. Rev geogr alp. $96(1): 1-14$

Mathers KL, Hill MJ, Wood CD, Wood PJ. The role of fine sediment characteristics and body size on the vertical movement of a freshwater amphipod. Freshwater Biol. 64:152-163.

Matthaei CD, Arbuckle CJ, Townsend CR. 2000. Stable surface stones as refugia for invertebrates during disturbance in a New Zealand stream. J N Am Benthol Soc. 19(1):82-93.

Matthaei CD, Townsend CR. 2000. Inundated floodplain gravels in a stream with an unstable bed: Temporary shelter or true invertebrate refugium? NZ J Mar Fresh. 34(1):147-156.

Meyer-Peter E, Müller R. 1948. Formulas for bed-load transport. Proc. 2nd Meeting, IAHR, Stockholm, Sweden, 39-64.

Negishi JN, Inoue M, Nunokawa M. 2002. Effects of channelisation on stream habitat in relation 
to a spate and flow refugia for macroinvertebrates in northern Japan. Freshwater Biol. $47: 1515-1529$.

Nelson PA, Venditti JG, Dietrich WE, Kirchner JW, Ikeda H, Iseya F, Sklar LS. 2009. Response of bed surface patchiness to reductions in sediment supply. J Geophys Res Earth Surf. 114(F2):F02005.

Palmer MA, Arensburger P, Martin AP, Denman DW. 1996. Disturbance and patch-specific responses: the interactive effects of woody debris and floods on lotic invertebrates. Oecologia. 105:247-257.

Palmer MA, Menninger HL, Bernhardt E. 2010. River restoration, habitat heterogeneity and biodiversity: a failure of theory or practice? Freshwater Biol. 55:205-222.

Pearsons TN, Li HW, Lamberti GA. 1992. Influence of Habitat Complexity on Resistance to Flooding and Resilience of Stream Fish Assemblages. Trans Am Fish Soc. 121:427-436.

Poff NL, Allan JD, Bain MB, Karr JR, Prestegaard KL, Richter BD, Sparks RE, Stromberg JC. 1997. The Natural Flow Regime. BioScience. 47(11):769-784.

Polvi LE, Lind L, Persson H, Miranda-Melo A, Pilotto F, Su X, Nilsson C. 2020. Facets and scales in river restoration: Nestedness and interdependence of hydrological, geomorphic, ecological, and biogeochemical processes. J Environ Manage. 265:110288.

QGIS.org. (2020). QGIS Geographic Information System. Open Source Geospatial Foundation Project. http://qgis.org.

Rachelly C, Weitbrecht V, Vetsch DF, Boes RM. 2018. Morphological development of river widenings with variable sediment supply. River Flow 2018, Lyon, France. E3S Web of Conferences 40:02007.

Reid DA, Hassan MA, Bird S, Pike R, Tschaplinski P. 2020. Does variable channel morphology lead to dynamic salmon habitat? Earth Surf Process Landforms, 45:295-311.

Rempel LL, Richardson JS, Healey MC. 1999. Flow refugia for benthic macroinvertebrates during flooding of a large river. J N Am Benthol Soc. 18(1):34-48.

Resh VH, Brown AV, Covich AP, Gurtz ME, Li HW, Minshall GW, Reice SR, Sheldon AL, Wallace JB, Wissmar RC. 1988. The Role of Disturbance in Stream Ecology. J N Am Benthol Soc. 7(4):433-455.

Rice SP, Buffin-Bélanger T, Lancaster J, Reid I. 2007. Movements of a macroinvertebrate (Potamophylax latipennis) across a gravel-bed substrate: effects of local hydraulics and micro-topography under increasing discharge. In: Habersack H, Piégay H, Rinaldi M, editors. Developments in Earth Surface Processes. 11:637-659. 
Richter B, Baumgartner J, Wigington R, Braun D. 1997. How much water does a river need? Freshwater Biol. 37:231-249.

Rohde S, Schütz M, Kienast F, Englmaier P. 2005. River widening: an approach to restoring riparian habitats and plant species. River Res Applic. 21:1075-1094.

Schwartz JS, Herricks EE. 2005. Fish use of stage-specific fluvial habitats as refuge patches during a flood in a low-gradient Illinois stream. Can J Fish Aquat Sci. 62(7):1540-1552.

Sedell JR, Reeves GH, Hauer FR. 1990. Role of refugia in recovery from disturbances: Modern fragmented and disconnected river systems. Environ Manage. 14:711-724.

Stanford JA, Lorang MS, Hauer FR. 2005. The shifting habitat mosaic of river ecosystems. SIL Proceedings, 1922-2010. 29(1):123-136.

Stevenson JA, Sun X, Mitchell NC. 2010. Despeckling SRTM and other topographic data with a denoising algorithm. Geomorphology. 114(3):238-252.

Strickler A. 1923. Beiträge zur Frage der Geschwindigkeitsformel und der Rauhigkeitszahlen für Ströme, Kanäle und geschlossene Leitungen [Contributions to the Question of a Velocity Formula and Roughness Data for Streams, Channels and Closed Pipelines]. Mitteilungen des Amtes für Wasserwirtschaft, 16. Eidgenössisches Dept. des Innern, Bern, Switzerland [in German].

Stubbington R. 2012. The hyporheic zone as an invertebrate refuge: a review of variability in space, time, taxa and behaviour. Mar Freshwater Res. 63:293-311.

Sueyoshi M, Nakano D, Nakamura F. 2014. The relative contributions of refugium types to the persistence of benthic invertebrates in a seasonal snowmelt flood. Freshwater Biol. 59(2):257271.

Sun X, Rosin PL, Martin RR, Langbein FC. 2007. Fast and effective feature-preserving mesh denoising. IEEE Trans Vis Comput Graph. 13(5):925-938.

Surian N, Rinaldi M. 2003. Morphological response to river engineering and management in alluvial channles in Italy. Geomorphology. 50(4):307-326.

Swanson FJ, Johnson SL, Gregory SV, Acker SA. 1998. Flood disturbance in a forested mountain landscape - interactions of land use and floods. BioScience. 48(9):681-689.

swisstopo: Federal Office of Topopgraphy. 2018. swissBOUNDARIES3D. https://opendata.swiss/en/dataset/swissboundaries3d-landesgrenzen

Tockner K, Stanford J. 2002. Riverine flood plains: Present state and future trends. Environ Conserv. 29(3):308-330.

Toro EF. 2001. Shock-Capturing Methods for Free-Surface Shallow Flows. New York: Wiley. 
Townsend CR, Scarsbrook MR, Dolédec S. 1997. The intermediate disturbance hypothesis, refugia, and biodiversity in streams. Limnol Oceanogr. 42(5):938-949.

van der Nat D, Schmidt AP, Tockner K, Edwards PJ, Ward JV. 2002. Inundation Dynamics in Braided Floodplains: Tagliamento River, Northeast Italy. Ecosystems. 5:0636-0647.

Vander Vorste R, Obedzinski M, Nossaman Pierce S, Carlson SM, Grantham TE. 2020. Refuges and ecological traps: Extreme drought threatens persistence of an endangered fish in intermittent streams. Glob Chang Biol. 26:3834-3845.

Vanzo D, Zolezzi G, Siviglia A. 2016. Eco-hydraulic modelling of the interactions between hydropeaking and river morphology. Ecohydrol. 9:421-437.

Vetsch D, Siviglia A, Bacigaluppi P, Bürgler M, Caponi F, Conde D, Gerke E,Kammerer S, Koch A, Peter S, Vanzo D, Vonwiller L, Weberndorfer M. 2020. SystemManuals of BASEMENT, Version 3.0. Laboratory of Hydraulics, Glaciology and Hydrology (VAW). ETH Zurich, Switzerland. Available from https://www.basement.ethz.ch. [28.05.2020].

Ward J, Tockner K, Schiemer F. 1999. Biodiversity of floodplain river ecosystems: ecotones and connectivity. Regul Rivers: Res Manage. 15:125-139.

Weber C, Nilsson C, Lind L, Alfredsen KT, Polvi LE. 2013. Winter Disturbances and Riverine Fish in Temperate and Cold Regions. BioScience. 63(3):199-210.

Weingartner R, Aschwanden H. 1992. Abflussregimes als Grundlage zur Abschätzung von Mittelwerten des Abflusses [Flow regimes as a basis for estimating mean discharge values]. Hydrologischer Atlas der Schweiz, Tafel 5.2. Bern, Switzerland [in German].

Wheaton JM, Brasington J, Darby SE, Sear DA. 2010. Accounting for uncertainty in DEMs from repeat topographic surveys: improved sediment budgets. Earth Surf Process Landf. $35(2): 136-156$.

Wilcock PR, Crowe JC. 2003. Surface-based Transport Model for Mixed-Size Sediment. J Hydrol Eng. 129(2):120-128.

Williams RD, Bangen S, Gillies E, Kramer N, Moir H, Wheaton J. 2020. Let the river erode! Enabling lateral migration increases geomorphic unit diversity. Sci Total Environ. 715:136817.

Williams DD, Hynes HBN. The Recolonization Mechanisms of Stream Benthos. Oikos. $27(2): 265-272$

Winterbottom J, Orton S, Hildrew A, Lancaster J. 1997. Field experiments on flow refugia in streams. Freshwater Biol. 37:569-580.

Wohl E, Bledsoe BP, Jacobson RB, Poff NL, Rathburn SL, Walters DM, Wilcox AC. 2015 a. The Natural Sediment Regime in Rivers: Broadening the Foundation for Ecosystem Man- 
agement. BioScience. 65(4):358-371.

Wohl E, Lane SN, Wilcox AC. 2015b. The science and practice of river restoration. Water Resour Res. 51:5974-5997.

Wood PJ, Boulton AJ, Little S, Stubbington R. 2010. Is the hyporheic zone a refugium for aquatic macroinvertebrates during severe low flow conditions? Fund Appl Limnol / Arch Hydrobiol. 176(4):377-390. 